\title{
Behavioral Economics, Internet Search, and Antitrust
}

\author{
ADAM CANDEUB ${ }^{*}$ \\ I. INTRODUCTION
}

Google's domination of online search in Europe and the United States has attracted antitrust scrutiny. ${ }^{1}$ The Federal Trade Commission ("FTC" or "the commission") recently concluded an investigation but declined to take major enforcement action, ${ }^{2}$ and investigation of the European Commission ("EC") continues to drag on. ${ }^{3}$ These investigations covered a variety of allegedly anticompetitive behavior, such as "manipulat[ing] Google search results to penalize competitors or to privilege other Google products and

\footnotetext{
* Professor of Law, Director of IP, Information, and Communications Law Program, Michigan State University College of Law.

${ }^{1}$ Leo Cendrowicz, The E.U. Probe: Is Google Rigging Its Search Results?, Time, Dec. 2, 2010, http:// www.time.com/time/business/article/o,8599,2034138,o0.html; Companies Ask EU Commission To Step in On Google Search Ranking Complaint, ITProPORTAL (Feb. 24, 2010), http://www.itproportal.com/2010/02/24/ companies-ask-eucommission-step-google-search-ranking-complaint/ (according to comScore, an internet data company, Google leads Internet searching in Europe, with an 82 percent market share, and enjoys 67 percent in the United States).

${ }^{2}$ Statement of the FTC, In the Matter of Google Inc., F.T.C. File No. 121-0120 (Jan. 3, 2013), available at

http://www.ftc.gov/os/caselist/1210120/130103googlemotorolastmtofcomm.pdf.

3 Frances Robinson, Google Amends Proposal to Settle EU Antitrust Investigation Complainants Get Four Weeks to Review Updated Plan, WALL ST. J., Oct. 28, 2013, http://online.wsj.com/news/articles/

SB10001424052702303471004579163423647198240.
} 
features." 4 In addition, numerous private antitrust suits have been filed against Google, though none so far successful. 5

These regulatory and judicial efforts have failed to fully define how search engines can behave anti-competitively. ${ }^{6}$ On one hand, legal commentary identifies numerous potential anti-competitive behaviors such as biasing organic search results, placing results from competitors in a disadvantaged way on the result screen, and excluding competing, specialized search engines.7 On the other hand, competition on the web is the proverbial "click away," strongly suggesting that consumer loyalty to Google results from providing superior services. Further, remedies for search bias seem unworkable as it is far from clear what unbiased search is-and regulating search algorithms raises a myriad of legal issues ranging from the First Amendment to trade secrecy. ${ }^{8}$

Rather than develop new tools for understanding whether or how search engines behave anti-competitively, regulators appear to rely upon traditional approaches, not specific to online behavior, assuming that market behavior online is not distinguishable from behavior in the brick and mortar world. For instance, using typical antitrust

\footnotetext{
4 Marvin Ammori \& Luke Pelican, Competitors' Proposed Remedies for Search Bias: Search "Neutrality" and Other Proposals, 15 J. INTERNET L. 1, 1 (2012) (noting that the EC's "two-year investigation" of Google has lasted several years and continues to drag on); Foo Yun Cheem, EU Sees Google Competition Deal After August, REUTERS, Feb. 22, 2013, available at http://www.reuters.com/article/2013/o2/22/us-eu-googleidUSBRE91LoEJ20130222; Leo Cendrowicz, The E.U. Probe: Is Google Rigging Its Search Results?, TIME, Dec. 2, 2010, http://

www.time.com/time/business/article/o,8599,2034138,oo.html; Companies Ask EU Commission To Step in On Google Search Ranking Complaint, ITPROPORTAL (Feb. 24, 2010), http://www.itproportal.com/2010/ 02/24/companies-ask-eu-commission-stepgoogle-search-ranking-complaint.
}

5 See Google, Inc. v. myTriggers.com, No. og CVH10-14836, 2011 WL 3850286 (Ohio Com. Pl. Aug. 31, 2011); TradeComet.com, Inc. v. Google, Inc., 693 F. Supp. $2 \mathrm{~d} 370$ (S.D.N.Y. 2010); Person v. Google, Inc., No. C 06-7297, 2007 WL 1831111 (N.D. Cal. June 25, 2007); KinderStart.com v. Google, Inc., No. C 06-2057, 2007 WL 831806 (N.D. Cal. Mar. 16, 2007).

${ }^{6} I d$.

7 See Robert H. Bork \& J. Gregory Sidak, What Does the Chicago School Teach About Internet Search and the Antitrust Treatment of Google?, 8 J. COMPETTTION L. \& ECON. 663, 664 (2012) (describing antitrust allegations); Geoffrey A. Manne \& Joshua D. Wright, Google and the Limits of Antitrust: The Case Against Google, 34 HARV. J.L. \& PUB. POL'Y $171,187,228$ (2011).

${ }^{8}$ See infra notes $17-26$ and accompanying text. 
analyses, the FTC found that Google's search rankings and presentation of search results did not warrant further regulatory concern. ${ }^{9}$ Because the cost of search is so low, the FTC reasoned that there is little chance that search cost will deter consumers from trying Google's competitors. Prominent critics argued that this conclusion applies established Chicago School antitrust teachings in a manner unsuited for the new, digital economy.10

This Article suggests that online market behavior may differ from the brick and mortar world and examines whether traditional antitrust reasoning and economic assumptions fully explain search behavior. In particular, behavioral tendencies related to habit and information costs may disrupt conventional economic assumptions. This Article suggests that searching the internet is quite taxing cognitively-it is a pain in the neck. Consumers' desire to decrease these cognitive costs may lead people to adopt hard-to-change habitual behaviors when using the internet.

If we establish habits and routines to allocate our scarce cognitive resources, these routines-like many other habits-can be quite difficult, i.e., costly, to break, creating high switching costs with possible anti-competitive implications. If Google search provides ways to lower these costs through convenient access to desired internet services such as email, YouTube, or maps, then there could be switching costs that develop as Google use becomes habituated. If these tendencies are magnified, as they often can be through network effects, it is at least possible that anti-competitive results may followso that competition is no longer a "click away."

To expand upon this point, I adopt the terminology of Nobel economics prize winner and intellectual pioneer of behavioral economics, Daniel Kahneman. He divides the mechanisms for control of human action between the automatic and involuntary (which he terms "System 1") and the effortful, deliberate, conscious, and introspective (which he terms "System 2"). ${ }^{11}$ One reviewer explained it

${ }_{9}^{9}$ See id.; see also infra note 38 and accompanying text.

10 Frank Pasquale \& Siva Vaidhyanathan, Borking Antitrust: Google Secures Its Monopoly Dissent, DISSENT (Jan. 4, 2013), http://www.dissentmagazine.org/blog/borking-antitrustgoogle-secures-its-monopoly ("Charged with enforcing antitrust laws and protecting a broad sense of consumer welfare, [the FTC] punted on its twenty-month antitrust investigation of Google. By doing so, the FTC not only adopted Bork as its patron saint. It put those who might hope to create the next big thing, the next Google, or the next Facebook, on notice: they should probably defer their dreams. Google will be free to bully small and emerging firms without the U.S. government riding to the rescue.").

${ }^{11}$ Daniel Kahenman, Thinking, Fast And Slow 20-24 (1st ed. 2011). 
this way: "It is System 1 that detects hostility in a voice and effortlessly completes the phrase bread and ... It is System 2 that swings into action when we have to fill out a tax form or park a car in a narrow space."12

System 2 is more "costly" in terms of time, effort, and energy, and its capacities for concentration and sustained thought. By contrast, System 1's largely automatic processes are instinctual or habitual. People can execute them with minimal use of cognitive effort. Indeed, we prefer System 1, often avoiding situations that require effortful reasoning. ${ }^{13}$

Framed in terms of System 1 versus System 2 tradeoffs, it is easy to see why consumers may elect to stick with a familiar web service, even when presented with claims of superiority by a rival, and why significant market share advantages, once established, may erode only slowly over time, if at all. In short, contrary to many assumptions in this debate, the cognitive cost of the click that initiates a switch to a competing service can be quite high.

A firm could take advantage of such switching costs with anticompetitive results. For example, Google is more than a search engine. Through its links to services such as news, email, and YouTube, Google provides a gateway to the web that minimizes search time-and thereby the cognitive and time costs of using the web. Habit, as furthered by network effects, could further lower these cognitive costs.

To adopt a metaphor from graph theory, a dominant search engine may constitute a "minimum spanning tree." These trees, which are mathematically defined concepts, connect "a set of points (representing cities, homes, or other locations) by the smallest amount of roadway, wire, or pipe."14 Google might serve as the internet's minimum spanning tree where the connection medium is not wire or pipe but cognitive cost or effort. In this sense, a dominant search engine could become a type of essential facility and thus raise antitrust issues.

This Article examines the current state of regulation of search engines and sketches a story of how behavioral economic tendencies,

12 Jim Holt, Two Brains Running, N.Y. TiMES, Nov. 25, 2011, http://www.nytimes.com/2011/11/27/ books/review/thinking-fast-and-slow-by-danielkahneman-book-review.html?pagewanted=all\&_r=o.

13 KAHENMAN, supra note 11 , at 39-48.

14 Steven S. Skiena, The Algorithm Design Manual 192 (2010). 
particularly those related to habit and Kahneman's System 1, could create significant costs for consumers to switch search engines. This article also suggests how these tendencies might render a search engine a type of "essential facility." which would of course raise antitrust concerns. A dominant search engine could become the cheapest way to access the web for most people, with competitors shut out because of high switching costs in terms of cognitive effort. Without putting forth a detailed antitrust case, this Article suggests a new way to analyze market power on the web that supports the possibility of viewing a dominant search engine as an essential facility. Finally, this Article responds to some of the objections to using behavioral approaches to antitrust.

\section{THE CURRENT DEBATE AND RECENT REGULATORY ACTION}

The question of whether Google's domination of the search market constitutes an antitrust violation has been debated for many years. With the FTC action in January 2013, this legal struggle has entered a new phase. The following section discusses the nature of the allegations against Google and how the FTC responded. This section concludes by questioning several of the assumptions made in these legal struggles and policy debates.

\section{A. Anti-Competitive Behavior By Search Engines}

Allegations of anti-competitive behavior against search engines typically involve search bias-either in a search engine's organic (unpaid for) search results or paid results (advertisements that appear on the side of the screen). In recent Senate hearings on Google, some complained that Google "'cook[s]' its algorithm ... rig[ging] its results, biasing [search results] in favor of [itself]."15 Oren Bracha and Frank Pasquale state the fear in this fashion: Google may "directly manipulate the flow of information-suppressing some sources while highlighting others-whether on the basis of intrinsic preferences or in response to inducements or pressures by others." 16

15 Joshua D. Wright, Moving Beyond Naïve Foreclosure Analysis, 19 GEO. MASON L. REv. 1163, 1189, (citing The Power of Google: Serving Consumers or Threatening Competition?: Hearing Before the Subcomm. on Antitrust, Competition Policy \& Consumer Rights of the S. Comm. on the Judiciary, 112th Cong. at 35 (statement of Jeff Katz, Chief Executive Officer, Nextag, Inc.)).

16 Oren Bracha \& Frank Pasquale, Federal Search Commission? Access, Fairness, and Accountability in the Law of Search, 93 CORNELL L. REV. 1149, 1165 (2008); see also Can Search Discrimination by a Monopolist Violate U.S. Antitrust Laws?, FAIRSEARCH 1, 
This algorithm "cooking" includes alleged Google discrimination against other specialty a/k/a "vertical" engines, like Yelp!, in favor of its own vertical engines and sites. ${ }^{17}$ Parties have also alleged that the 2007 introduction of Google's Universal Search, which goes beyond searching websites to searching "images, videos, news, maps, and places," favors Google's facilities such as "Google Maps, Google Places, and Google Products, over competing specialized search providers, such as MapQuest, Yelp!, Foundem, and Nextag." 18

In response, many believe that Google has no incentive to engage in anti-competitive behavior. ${ }^{19}$ In a highly influential article, the late Robert Bork, famed Supreme Court nominee, appellate judge, and a leader of the Chicago School of antitrust, ${ }^{20}$ and J. Gregory Sidak, chairman of Criterion Economics consulting, scholar, and long-time Washington telecommunications insider, argue that Google's ranking procedures have one overriding goal: "attract and retain" search

http://www.fairsearch.org/wp-content/uploads/2011/o7/Can-Search-Discrimination-bya-Monopolist-Violate-U.S.-Antitrust-Laws1.pdf (last visited Feb. 27, 2013) ("Given Google's monopoly grip on search and search advertising, Google's customers and competitors increasingly worry that Google has both the incentive and ability to manipulate its search results in ways that steer users to its own (possibly inferior) services and away from competitors-and thus deprive these competitors of the customers they need to survive."); see also James Grimmelmann, The Elephantine Google Books Settlement, 58 J. OF THE COPYRIGHT SOCIETY OF THE U.S.A. 701, 719 (2011) (the settlement "was formally nonexclusive-nothing in it would have prohibited copyright owners from licensing anyone else to sell their books. But in a world with orphan works, formal nonexclusivity will often be practically worthless. Google would have had a good-to-go license; its competitors will have no one to turn to.").

17 Daniel A. Crane, Search Neutrality as an Antitrust Principle, 19 GEO. MASON L. REv. 1199, 1200-01 (2012) ("In this paradigm, original sin entered the world with vertical integration. Once search engine companies began to integrate vertically by operating websites, they were tempted to manipulate the previously objective search algorithms to favor their own sites in their search results. Thus, in response to a query suggesting an interest in finding driving directions, Google might prioritize a link to Google Maps in its search results at the expense of MapQuest. Given a sufficient dominance in search, Google might then erode MapQuest's market position over time and entrench Google Maps as the dominant driving directions site.").

${ }^{18}$ Ammori \& Pelican, supra note 4, at 10.

19 See Pasquale \& Vaidhyanathan, supra note 10.

${ }^{20}$ See ROBERT BORK, THE ANTITRUST PARADOX A POLICY AT WAR WITH ITSELF (1993, originally published 1978) (Bork's classic, The Antitrust Paradox A Policy at War with Itself, the echt-statement of the Chicago School of economics, argues for antitrust intervention only in narrow circumstances). 
engine users. ${ }^{21}$ Arguing that this goal promotes innovation, they conclude that "punishing Google for being the most effective search competitor would harm consumers and thus contradict the recognized purpose of antitrust law." 22 They contend that punishing Google would limit innovation and "dynamic efficiency."

Bork and Sidak also point out that Internet search is a two-sided market. A two-sided market comprises two sets of "customers": advertisers and consumers with Google acting as the platform that connects the two "sides." This market structure gives Google the incentive to attract the maximum number of advertisers and users. Bork and Sidak go further, positing that this two-sidedness results in "Google's incentives [to] align with promoting competition and consumer welfare." 23 Google has these incentives because its largest source of revenue is from advertising, and support from advertisers depends on consumers using Google.

Bork and Sidak believe that because "consumers can switch to substitute search engines instantaneously and at zero cost constraints," Google has no incentive to minimize access or to somehow limit output or quality to anti-competitive effect. ${ }^{24}$ To the contrary, because Google is a two-sided service, it has the incentive to get as many users as it can on-board. If it fails to do so, consumers will "click" away. Rejecting the notion that Google can act as a gateway to limit competition, Bork and Sidak defend the notion that competition is always a click away "due to the Internet's open architecture." 25 They contend that "the openness of the Internet always allows consumers to sample competing sites." 26

\section{B. Remedies}

In addition to the serious arguments as to whether Google presents any competitive problems, the proposed remedies present serious legal and practical problems. First, those who do not support antitrust action respond that even if Google "cooks" its algorithm, it is

\footnotetext{
${ }^{21}$ Bork \& Sidak, supra note 7 , at 664.

${ }^{22}$ Id. at 665 .

${ }^{23}$ Id.

24 Id.

$25 I d$.

${ }^{26} I d$. at 672 .
} 
unclear how a "raw" search algorithm tastes. In other words, while those concerned about search engine manipulation argue for "search neutrality," it may not exist because all search engines employ content-based decisions that may very well prioritize for perfectly innocuous, i.e., sound business and engineering, reasons. ${ }^{27}$ Many have argued that there are sound economic reasons for allowing "search bias" as natural and desirable competition that allows search engines to experiment with consumer-beneficial vertical relationships with other firms. ${ }^{28}$

Further, even if it were possible, or desirable, to define what constitutes a "neutral search," regulating Google's search algorithm still presents numerous legal obstacles. Such regulation may be unconstitutional, as regulating Google's search algorithm is regulating speech and, therefore, entitled to First Amendment protection. Eugene Volokh and Donald M. Falk have argued that Google, Microsoft's Bing, and Yahoo! search engines exercise editorial judgment about what constitutes useful information and convey that information-which is to say, they speak-to their users. In this respect, search engines are "analogous to newspapers and book publishers ... and [therefore] are shielded by the First Amendment."29 Many have also argued that trade secret law would bar any forced disclosure of the algorithm..$^{30}$

Other proposed remedies recall the Federal Communications Commission's "structural separation" between the Bell Telephone and innovative computer services using the phone network. ${ }^{31}$ They include

27 Compare Frank Pasquale, Dominant Search Engines: An Essential Cultural \& Political Facility, in The NEXT DIGITAL DECADE: ESSAYS ON THE FUTURE OF THE INTERNET 401, 415 (Berin Szoka \& Adam Marcus, eds., 2010), and Bracha \& Pasquale, supra note 16, with James Grimmelmann, Some Skepticism About Search Neutrality, in THE NEXT DIGITAL DECADE: ESSAYS ON THE FUTURE OF THE INTERNET 435 (Berin Szoka \& Adam Marcus, eds., 2010), and Eric Goldman, Search Engine Bias and the Demise of Search Engine Utopianism, 8 YALE J.L. \& TECH. 188 (2006).

${ }^{28}$ See Geoffrey A. Manne \& Joshua D. Wright, If Search Neutrality Is The Answer, What's The Question?, 2012 COLUM. BuS. L. REV. 151 (2012); Goldman, supra note 27.

29 EUgene Volokh \& DONALD M. FALK, FirSt AMENDMENT PROTECTION FOR SEARCH ENGINE SEARCH RESULTS 889 (Apr. 20, 2012), available at http://www.volokh.com/wpcontent/uploads/2012/05/ SearchEngineFirstAmendment.pdf.

$3^{\circ 0}$ Manne \& Wright, supra note 28.

31 Adam Candeub, Trinko and Re-Grounding the Refusal to Deal Doctrine, 66 U. Pitt. L. Rev. 821, 833 (2004-2005). 
splitting Google into a "general" search company and a "specialized" search company, requiring additional disclosure of Google's search algorithm, allowing competitors to crawl (i.e., take electronic information from Google's servers) over its resources without reciprocal rights. Even strong consumer advocates find these remedies either unworkable or unfair, concluding that such remedies may even "threate[n] consumer welfare, competition, and innovation." 32

\section{The FTC Investigation of Google}

The recent settlement of the Federal Trade Commission investigation of Google addressed several concerns related to Google's strategy and market position: (1) Google, with its $\$ 12.5$ billion acquisition of Motorola in 2012, owned certain "essential" patents used on smart phones, laptop and tablet computers, and gaming consoles. Competitors worried these patents could be used to stifle competition; 33 (2) the ability of advertisers to manage ad campaigns on Google's AdWords platform and on rival ad platforms combined with Google's use of content from other websites hurt competition;34 and (3) Google's search algorithm which allegedly skewed results towards Google sites and advertisers, and Google's "universal search" prominently displays targeted Google properties in response to specific categories of searches, such as shopping and local business searches. Google's practices allegedly hurt other competitor "vertical search" engines, i.e., specialized engines such as Yelp! or Ebay. 35

The settlement responded to these allegations in the following manner. First, with respect to the disputed patents, Google agreed to refrain from both seeking injunctions against a willing licensee, either in federal court or at the International Trade Commission ("ITC") or blocking the use of any standard-essential patents that the company has previously committed to license on fair, reasonable and nondiscriminatory ("FRAND") terms. ${ }^{36}$ Second, Google removed

\footnotetext{
32 Ammori \& Pelican, supra note 4, at 13.

33 Statement of the FTC, In the Matter of Google Inc., supra note 2.

34 F.T.C. News Release, Google Agrees to Change Its Business Practices to Resolve FTC Competition Concerns in the Markets for Devices like Smart Phones, Games and Tablets, and in Online Search (Jan. 3, 2013), available at http://www.ftc.gov/opa/2013/o1/google.shtm.
}

$35 I d$.

${ }^{36}$ Id. 
limitations on the use of its online search advertising platform, AdWords, to allow advertisers to use, more easily, online advertising campaigns across multiple platforms. In addition, Google will give websites the ability to opt out of Google's vertical search offerings, while still having them appear in Google's general, or "organic," web search results. ${ }^{37}$

Third, the FTC stated that it "evaluated Google's introduction of "Universal Search"'-a product that prominently displays targeted Google properties in response to specific categories of searches, such as shopping and local business search. In addition, the FTC examined "the allegation that Google altered its search algorithms to demote certain vertical websites in an effort to reduce or eliminate a nascent competitive threat." ${ }^{8}$ (As discussed below, "Vertical" refers to specialized search engines, such as Mapquest that competes with Google's specialized map search "Google maps").

In rejecting these claims, the FTC engaged in a typical antitrust analysis, treating search like any other good. Google produces search results, and these results are to be analyzed like any other product. Innovation in search is to be weighed against Google's possible anticompetitive behavior. The FTC determined that whatever injury Google search inflicted on competitors was smaller than the consumer benefits of its better search results and product design.

Specifically, the FTC concluded that while Universal Search and the Google algorithm could harm certain competitors, these Google features could be justified as innovations that improve user experience. 39 The Commission's analysis was straightforward. It viewed the "key issue ... [as] whether Google changed its search results primarily to exclude actual or potential competitors and inhibit the competitive process, or on the other hand, to improve the quality of its search product and the overall user experience." 40 In general, it

37 Id.

${ }^{38} I d$.

39 Id. ("The totality of the evidence indicates that, in the main, Google adopted the design changes that the Commission investigated to improve the quality of its search results, and that any negative impact on actual or potential competitors was incidental to that purpose. While some of Google's rivals may have lost sales due to an improvement in Google's product, these types of adverse effects on particular competitors from vigorous rivalry are a common byproduct of 'competition on the merits' and the competitive process that the law encourages.").

${ }^{40} \mathrm{Id}$. 
found that Google's search improved consumer experiences so that it constitutes "competition on the merits" rather than exclusion. ${ }^{41}$ First, as far as Google's prominent display of its own vertical search results, i.e. Google shopping results, the Commission concluded that Google's motivation was not to exclude other shopping vertical search engines but to enhance consumer experience by better answering search queries. To reach this conclusion, the Commission pointed to evidence "that Google would typically test, monitor, and carefully consider the effect of introducing its vertical content on the quality of its general search results, and would demote its own content to a less prominent location when a higher ranking adversely affected the user experience." 42

Similarly, the Commission examined the allegations that Google acted in an anti-competitive manner in its treatment of competitor "vertical searches." It was alleged that "for shopping queries, Google demoted all but one or two comparison shopping properties from the first page of Google's search results to a later page." The Commission conceded that this search could hurt Google's competitors in shopping search in favor of its own "shopping vertical." Again, it found that this search effect reflected a "reasonable product" design. It declined to "second-guess a firm's product design decisions where plausible procompetitive justifications have been offered, and where those justifications are supported by ample evidence." 43

\section{Assumptions in the Debate}

The FTC decision made several key assumptions about market behavior. As mentioned above, leading Google critics argue that the FTC in effect channeled the views of the late Robert Bork and J. Gregory Sidak in its decision.44 Bork and Sidak wrote a 2012 paper that set for the typical Chicago School arguments against antitrust action. 45 Their argument, as the FTC appeared to agree, was that the costs of getting to Google and its competitors are the same. Or, as

\footnotetext{
${ }^{41} I d$.

${ }^{42}$ Id.

43 Id.

44 Pasquale \& Vaidhyanathan, supra note 10.

45 Bork \& Sidak, supra note 7.
} 
Bork and Sidak explicitly say, competition is just a costless click away. ${ }^{46}$

\section{A BEHAVIORAL MOVE IN INTERNET COMPETITION LAW?}

Departing from standard economic analyses that portray consumer choices as deliberate selections among alternatives ranked according to their anticipated contributions to personal utility, a behavioral model recognizes human tendencies to eschew difficult calculations in favor of "cognitive ease." Or, more precisely, people who face costs in thinking in deliberative, analytic ways make different choices than they would if choosing were costless-which standard economic analyses tend to assume. Generic observation and the research of psychologists like Kahneman and Tversky suggest that people, in fact, do face such costs. The following section examines some background assumptions of a behavioral approach and then examines some implications for competition law and internet law and policy.

\section{A. System 1/ System 2}

In 2002, Daniel Kahneman won the Nobel Prize for his research in behavioral economics, much of it conducted with his late colleague Amos Tversky. They claimed, contrary to the rational actor model, that individuals often make economic decisions without making complete comparative benefit calculations. In his bestseller Thinking Fast, Thinking Slow, Kahnemann collects the strains of decades of his research. .7 The result is a remarkably recognizable picture of human beings-as sometimes deliberate, calculating and explicitly rational, but also often running on autopilot. As Kahneman and others, such as Thalman and Cass Sunstein in their book, Nudge, have recognized, realizing that people are not perfect calculators of their own utility can have important policy ramifications. $4^{8}$

Kahneman postulates the existence of two choice systems that control human action and decision-making: System 1 does fast, intuitive thinking and System 2 does slow, deliberate "hard" thinking.

\footnotetext{
${ }_{46}$ Bork \& Sidak, supra note 7, at 672 (consumers "can and do use other search engines at zero switching cost and navigate directly to websites").

47 See KAHNEMAN, supra note 11.

48 RichaRD H. THALER \& CASS R. SUNSTEIN, NudGE: IMPROVING DECISIONS ABOUT HEALTH, WEALTH AND HAPPINESS (2009).
} 
System 1 operates automatically and quickly, with little or no effort or sense of voluntary control. System 2 monitors System 1, correcting its errors, but System 2 does so sparingly because it faces limits in terms of human effort and cognitive abilities. 49

Human beings prefer for a variety of different reasons what Kahneman calls "cognitive ease," which is associated with System 1 guided behavior. Human beings are more favorably disposed towards words or experiences to which they have already been exposed and easily understand. Psychologists postulate the "exposure effect" under which we prefer familiar situations because they have been deemed safe..$^{\circ}$ Easy tasks, guided by System 1 intuitions, put one in a good mood. ${ }^{11}$ System 1 "is generally very good at what it does: its models of familiar situations are accurate, its short-term predictions are usually accurate as well." 52

But, System 1 has biases as well and often makes mistakes. Perhaps most important, for the purposes of market behavior, is System 1's avoidance of careful rational calculation in favor of an established habit-even when careful calculation would result in a better, "more rational" choice. Further, System 1 "cannot be turned off." 53 Thus, individuals can persist in System 1-guided behaviors even though it may seem "rational" to make other choices.

Further exacerbating the possibility of persisting in System 1-sub optimal results, human beings do not like to use "System 2." The possibility of sub-optimal results is quite real because System 2 is, to use Kahneman's term, "lazy." It tires quickly because, when used rapidly, it consumes limited stores of the energy sources required to fuel the System 2 cognitive machinery. People tend to avoid strenuous mental effort, as it demands "self-control, and the exertion of selfcontrol is depleting and unpleasant." 54 This is perhaps not surprising as studies have shown that effortful mental activity consumes considerably more metabolic energy than System 1 decision-making. .55

\footnotetext{
${ }^{50}$ Id. at 66-68.

${ }^{51} I d$. at $68-70$.

$5^{2} I d$. at 25.

53 Id.

$54 \mathrm{Id}$. at 42.

${ }_{55}$ Id.
}

49 KAHNEMAN, supra note 11 , at 408. 
It seems quite advantageous, therefore, for businesses to make buying their products a System 1-guided habitual behavior. Indeed, the annals of capitalism are of full of such efforts. For instance, toothpaste never became popular until Pepsodent started to market the pleasure of having "film free" teeth and adding peppermint to its paste. Apparently, the peppermint played a role as the cue for the behavior of brushing and the "film free" teeth became the reward. People began to crave the cue-the peppermint-and the associated behavior, brushing, because it was associated with the reward: filmfree teeth. 56

Recent advances in brain science have brought new understanding to habit formation, adding support to the cue-reward model. Apparently, complex behaviors and sequences of behaviors can be "chunked," i.e., grouped together in the mind as a habit. Such batched behaviors are characterized by activity in the amygdala, an area associated with non-reflective activity. With chunked behaviors, there is little activity from the frontal lobes or other parts of the brain. 57 Thus, it seems at least some support that System 1 and System 2 behaviors have some basis in neurophysiology.

\section{A. Essential Facilities and Behavioral Tendencies}

The question this section examines is whether a firm could take advantage of System 1 behavior to make its search engine the portal to the web with the lowest cognitive cost. In other words, due to habit and web design, a search engine could be the "easiest" way for consumers to access those websites and services that they most often use. In this fashion, a search engine could be a "minimum spanning tree" of cognitive effort-a term examined above. Using any other search engine could incur significant switching costs. For instance, if one is habituated to using Google shopping, Gmail, YouTube, and Google Maps, one would face significant costs in changing one's habits-costs that might be greater than the benefits derived from using different search engines. In this way, a search engine could become an essential facility and thus raise potential antitrust concerns.

One of the more controversial doctrines in antitrust law, the "essential facilities" doctrine, holds that where there is an input required by a particular market and one firm controls that input,

\footnotetext{
${ }^{6}$ Charles Duhigg, The Power of Habit: Why We Do What We Do in Life and Business 5659 (2012).
}

57 Id. at 12-18. 
courts can compel that firm to offer competitors access to the input. ${ }^{58}$ The essential facilities doctrine is typically set forth as a four prong test: (1) a monopolist controls the essential facility; (2) a competitor is unable to practically or reasonably duplicate the essential facility; (3) access has been denied to a potential competitor; and (4) access is feasible.59 If this test is met, a court may mandate access to the essential facility as a remedy.

Though never formally adopted by the Supreme Court, the doctrine derives from United States. $v$. Terminal R. R. Ass'n of St. Louis.60 The case's history is interesting, and the railroad network bears important similarities to the internet. In 1889 , robber baron Jay Gould and several railroad companies formed a joint venture that gained ownership of the railroad terminals that controlled access to a key bridge spanning the Mississippi and thereby controlled railroad traffic crossing the Mississippi River. ${ }^{61}$ The bridge was "essential" because, in the $19^{\text {th }}$ century, twenty-four railroads terminated at the St. Louis hub through which they had to pass to connect to the traffic

\footnotetext{
$5^{8}$ JOINT COMMENTS OF THE AMERICAN BAR ASSOCIATION'S SECTION OF ANTITRUST LAW, SECTION OF INTELLECTUAL PROPERTY LAW AND SECTION OF INTERNATIONAL LAW AND PRACTICE ON THE REPORT OF THE STUDY GROUP ON THE ANTIMONOPOLY ACT OF JAPAN 3 (2004) ("The United States Supreme Court has made clear that it has never recognized the essential facilities doctrine, and it recently declined the opportunity to endorse or repudiate the doctrine."); HERBERT HOVENKAMP, FEDERAL ANTITRUST POLICY: THE LAW OF COMPETITION AND ITS PRACTICE, 336 (4th ed. 2011) (arguing that Terminal Railroad "involve[ed] an agreement among multiple firms who controlled the facility" and, consequently is not a good "ancestor for the essential facilities doctrine").
}

59 MCI Commc'ns v. Am. Tel. and Tel. Co., 708 F.2d 1081, 1133 (7th Cir.1983) (While case law does not explicitly explore the concept from an economic perspective, "feasibility" has an economic meaning. Access is feasible if a given facility can support multiple efficient competitors. This principle can guide access regulation); see also Adam Candeub, Trinko and Re-Grounding the Refusal to Deal Doctrine, 66 UNIV. OF PITT. L. REV. 821, 829-30 (2005) ("Under MCI Communications Corp. v. AT\&T, usually identified as the most significant modern explication of the doctrine, the essential facilities four-part test requires a showing of '(1) control of the essential facility by the monopolist; (2) a competitor's inability practically or reasonably to duplicate the essential facility; (3) the denial of the use of the facility to a competitor; and (4) the feasibility of providing the facility'... the Supreme Court never has recognized this doctrine and declined to rule on it in Trinko, but support for the doctrine is generally believed to be found in the Terminal Railroad case.").

60 United States v. Terminal R.R. Ass'n. of St. Louis, 224 U.S. 383, 391-92, 411 (1912).

${ }_{61}$ Id. at 391-95; see also Keith N. Hylton, Economic Rents and Essential Facilities, 1991 B.Y.U. L. REV. 1243, 1273. 
to the West. ${ }^{62}$ The Supreme Court, as a remedy, required Gould's joint venture to allow non-member railroads use of the terminal railroads that accessed the bridge on "just and reasonable terms," i.e., the ancient standard for common carriage rates. ${ }^{63}$

Could a search engine be an essential facility? The definition is famously vague. It requires that there be some input that, like the bridge over the Mississippi River and the surrounding railroad network around St. Louis, cannot be practically reproduced. On one hand, saying Google is an essential facility is absurd. After all, there are thousands of competitor search engines. Unlike having to travel hundreds-perhaps thousands-of miles to access another railroad bridge over the Mississippi, one need only type in a different name in the URL bar.

Some "argue that Google's ranking of its specialized results above competitors' results deprives competitors of an essential facility: being displayed high on a Google search results page."64 Bork and Sidak demolish this idea. Going through the legal prongs, they conclude that "Google general search pages are not an essential facility controlled by a monopolist," for the simple reason that Google is not a monopolist.65 There are plenty of competitor search engines. Similarly, as far as the second prong: "a competitor is unable to practicably or reasonably duplicate the essential facility,"66 Bork and Sidak argue that competitor search engines do, in fact, duplicate what Google does. Third, Bork and Sidak deny that Google "blocks" access to a potential competitor by placing the competitor lower down on the search result page. Rather, they argue that:

For a competitor not to be ranked within the top search results does not imply that Google has denied access to this spot. It simply means that Google's algorithm has determined that other links are more likely to answer a consumer's particular query ... Any competitor can

\footnotetext{
62 James R. Ratner, Should There Be An Essential Facility Doctrine?, 21 U.C. DAVIS L. REv. 327,335 (1988).

63 Hylton, supra at 61, at 1274.

64 Bork \& Sidak, supra note 7, at 666.

${ }^{6} \mathrm{Id}$. at 679 .

${ }^{66} I d$.
} 
become a top search result by providing the site that consumers want to visit the most. ${ }^{67}$

Finally, they point out that demanding access to Google's top ranked results would involve intractable problems. ${ }^{68}$ Google would lose the marketing costs expended to encourage consumers to use its services, and competitors would lose incentives to build their own. ${ }^{69}$ Further, Google would likely have to disclose its search algorithm, and courts or regulators would have to impose a "neutral" algorithm-a problematic remedy as discussed above on regulatory and First Amendment grounds.

But, this Article's interpretation of Google's essential facility differs from that of Bork and Sidak. It questions their initial claim that the Google's essential facility is its search results. Instead, Google's essential facilities are more plausibly the links above its search box, notably its YouTube and Google Books links. Or, even more broadly, the portal or interface that Google provides to the web. These wellchosen links provide easy, low cognitive access to the web, particularly if Google use is reinforced by habit. In this way, people use Google because System 1 drives its use and switching to a competing search engine would require System 2 analysis-something human beings tend to avoid.

Google's acquisition of highly used, often unique internet resources, such as YouTube and Google Books, and Google's placement of their links in easy-to-find places may reflect an effort to encourage habit formation and perhaps consign a consumer's use of Google to System 1. Consider Google's browser page. Its links, such as Google News, YouTube, Gmail, Google Books, combine web resources that arguably constitute a constellation of the best specialized search engines on the web. The YouTube video collection is truly unique and impossible to replicate because it reflects millions of videos from millions of viewers collected over many years. $7^{70}$

\footnotetext{
67 Id. at 682 .
}

${ }^{68} \mathrm{Id}$. at $684-85$.

$69 \mathrm{Id}$. at 685 .

70 John B. Meisel, Economic and Legal Issues Facing Youtube and Similar Internet Hosting Web Sites, 12 J. INTERNET L. 1, 10 (2009) ("The numbers depicting the current audience and inventory of available uploaded video clips for YouTube are staggering. Users access YouTube's Web site to view more than a billion video clips most days. YouTube has, by far, the largest market share (about 34 percent) for online video Web sites with an audience estimated at 78 million unique monthly visitors in the United States."). 
Similarly, the Google book repository-while potentially replicable by a firm with enough money-reflects years of technical and legal investment. While it is certainly true that anyone can scan books, the Google Books settlement-the legal resolution of numerous copyright claims-arguably puts Google Books in a unique situation. Indeed, the Google settlement, which creates the Book Rights Registry and has exclusive authority to collect fees for orphaned works, has rendered it essential because it has become the de facto exclusive clearinghouse for copyright holders. As James Grimmelman points out, the settlement "puts Google in a highly privileged position for book search and book sales ... The authors and publishers settled voluntarily with Google, but there is no guarantee they will offer similar terms, or any terms at all, to anyone else."71 Further, as Grimmelman points out, the settlement gives Google the ability to offer books at low transaction costs: it allows "Google a clean release from the transaction-cost madness. All those pesky claims from authors who cannot be found or will not play ball just go away."72

The point is not that Google search-or even YouTube or Google Books-constitutes an "essential facility" under the classic MCI definition discussed above. Rather, Google's strategy of acquiring properties, such as YouTube and Google Books, and placing them on its launch page makes Google an ever more attractive place to begin one's internet search. And it increases one's likelihood of staying on Google and Google-owned internet property. This use, in turn, will make Google, and its property, even cheaper to use in terms of cognitive cost, as its use becomes subject to System 1 control-and further increase Google's cognitive cost advantage in relationship to its competitors. In this way, Google as a whole may constitute an essential facility.

${ }^{11}$ James Grimmelmann, In Google We Antitrust, TPMCAFÉ BOOK CLUB, Jan. 15, 2009, http://web.archive.org/

web/20090119015948/http://tpmcafe.talkingpointsmemo.com/2009/01/15/in_google_w e_antitrust; see also Randal C. Picker, The Google Book Search Settlement: A New Orphan-Works Monopoly?, 5 J. COMP. L. \& ECON. 383 (2009) (examining the opt-out provision and the antitrust issues it raises); Pamela Samuelson, Google Book Search and the Future of Books in Cyberspace, 94 MINN. L. REv. 1308, 1335 (2010) (arguing that the settlement create an effective monopoly); but see Einer Elhauge, Why the Google Books Settlement Is Procompetitive, 2 J. LEGAL ANALYSIS 1 (2010) (defending the settlement against antitrust law challenge).

72 James Grimmelmann, How to Fïx The Google Book Search Settlement, 12 J. INTERNET L. 1, 14 (2009). 
C. Does Google Act as a Sort of "Minimum Spanning Tree of Cognitive Effort?"

Minimum spanning trees, an important concept in graph theory algorithms and computer programming, connect "a set of points (representing cities, homes, or other locations) by the smallest amount of roadway, wire, or pipe."73 We take the concept of a minimum spanning tree and suggest that Google serves as the internet's minimum spanning tree when the connection medium is not wire or pipe, but mental effort. Consider the following set of points.74 Each of the lines that connect the points has different weights. The bold, unhatched line is the tree that connects all of the dots using the lines with the least weight, as Figure 1 illustrates. The bold, unhatched tree is the minimum spanning tree of this set of points.

Figure 1

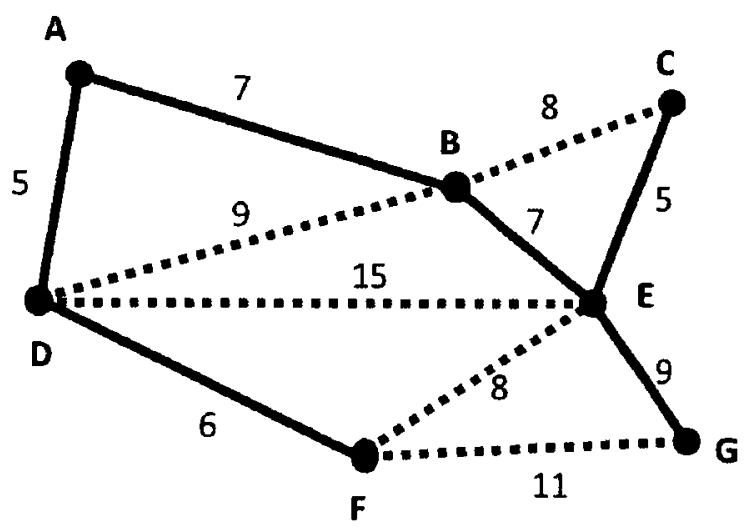

Take this simple idea and apply it to internet search. The vertices represent places that people want to go frequently-search engines, email services, news, maps, etc. The numbers reflect cognitive cost. The minimum spanning tree of the internet under this conceptualization is the lowest cognitive cost for getting to these places. Figure 2 illustrates this idea.

73 Steven S. Skiena, The Algorithm Design MaNual 192 (2009).

74 Minimum Spanning Tree: Kruskal's Algorithm, PROGRAMMING PRAXIS (Apr. 6, 2010), http:// programmingpraxis.com/2010/04/06/minimum-spanning-tree-kruskalsalgorithm. 
Figure 2

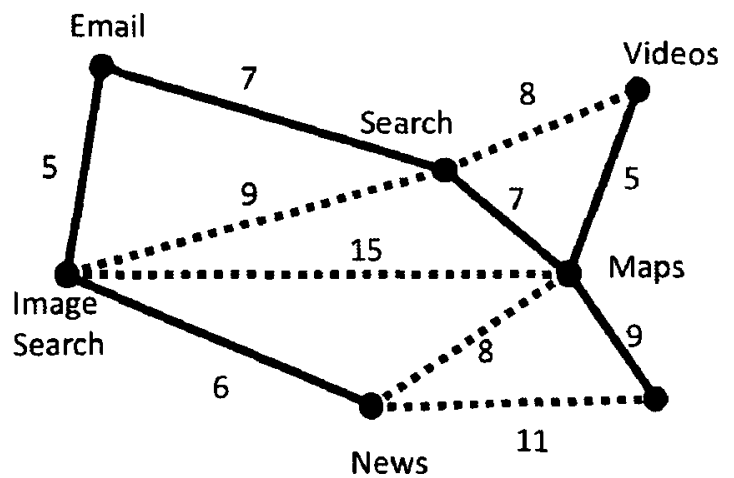

If the vertices are all Google or Google-affiliated sites, the internet's minimum spanning tree, would look something like that in Figure 3 below.

Figure 3

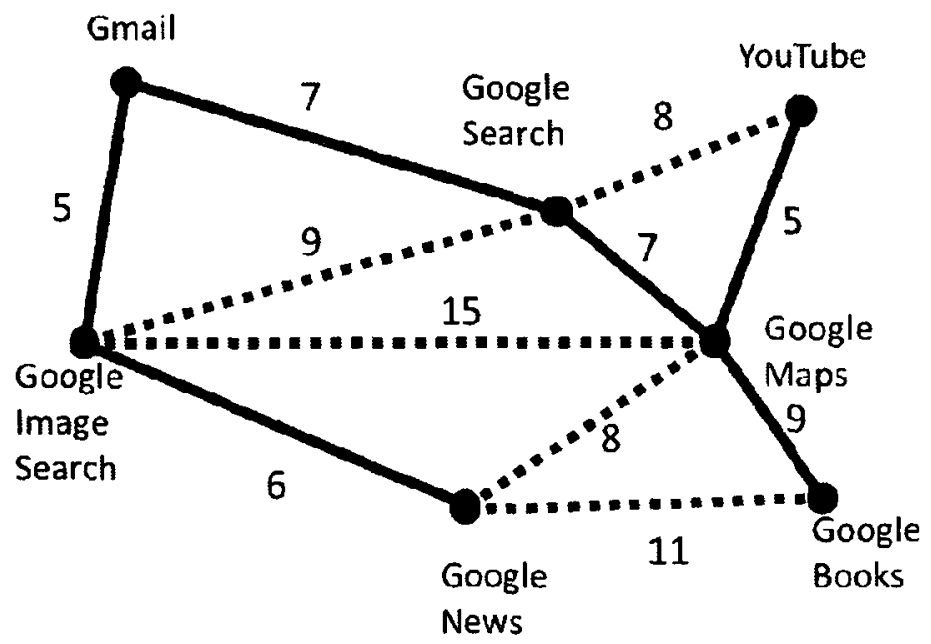

The antitrust implications of viewing the Google launch page as the Internet's minimum spanning tree is intriguing. On one hand, Google's minimum spanning tree provides an undeniable cognitive cost edge against competitors, making entry more difficult and raising rivals' costs. The feedback mechanisms discussed above and the acquisition of unique internet services, would increase usage in these 
sites-which would further lower the cognitive cost of using Google sites, increasing the cost difference between Google's minimum spanning tree and any competitors' way to obtain one's desired material from the web.

Viewed in this way, the "Google spanning tree" presents interesting essential facility questions. Under the accepted definition mentioned above, a (1) monopolist controls the putative essential facility; (2) a competitor is unable practicably or reasonably to duplicate the essential facility; (3) access has been denied to a potential competitor; and (4) access is feasible. 75 Google's minimum spanning tree could pass that test.

First, Google by definition has exclusive control over the spanning tree. Second, a competitor really cannot practically duplicate the spanning tree. Recall that Bork and Sidak point out that Google is not a monopolist because there are plenty of other search engines. ${ }^{76}$ But, Google's minimum spanning tree is unique in two ways. Because frequent use lowers the cost of using it and transiting to other sites, Google offers its users a way to interface at a uniquely lower cost. While there are many search engines, only Google offers its unique cost profile for navigating the web. Further, competitors cannot duplicate many of Google internet resources, such as YouTube and Google Books. These unique resources, of course, increase use and further decrease the cognitive cost of using Google.

Third, by definition, Google does not provide access to its unique, low cost way of access the web. Fourth and finally, a dominant search engine could give "access" by sharing some of the links on its launch page with competitors in some fashion. The precise contours of such access are beyond the scope of this Article.

\section{Empirical Support for this Story}

Whether habit-driven online behavior, in fact, develops in order to avoid high search costs and, in turn, creates high switching costs once a habit is in place is, of course, an empirical question. If people do not place a high cognitive cost on internet searching, then it is unlikely that they will develop habits to avoid such search. Thus, this set of

75 MCI Commc'ns v. Am. Tel. and Tel. Co., 708 F.2d 1081, 1132-1133 (7th Cir.), cert. denied, 464 U.S. 891 (1983). While case law does not explicitly explore the concept from an economic perspective, "feasibility" has an economic meaning. Access is feasible if a given facility can support multiple efficient competitors.

${ }^{76}$ Bork \& Sidak, supra note 7 , at 667 . 
behavioral concerns would have no implications for regulatory policy whatsoever.

A growing body of empirical research suggests that consumers find search activities on the internet to be extremely costly-and avoid these costs through habit and other heuristics that may results in suboptimal market results. First, an early and consistent finding is that people do not like search and do not do very much of it-despite it being only a click away. For instance, Eric J. Johnson and his coauthors found almost a decade ago that consumers in fact do very few searches and do not extensively review these searches. Johnson and his co-authors propose that cognitive costs associated with search create a type of lock-in behavior. 77

More recent studies make similar findings. Erik Brynjolfsson, Astrid A. Dicky, and Michael D. Smith show that price dispersion persists in the Internet and that this dispersion is largely due to search cost. ${ }^{8}$ Most recently, Lynn Sillipigni Connaway, Timothy J. Dickey, and Marie L. Radford, show in a large study of information seeking in academic and everyday environments that time and convenience is a dominant factor in information-seeking behaviors. 79

Anindya Ghose and Panagiotis G. Ipeirotis, using various techniques to quantify the cost of time and effort and benefits of incremental search, find that on average, the effort of continuing to search an extra page on search engines costs $\$ 39.15$, while the effort of continuing to search an additional screen position on the same page costs $\$ 6.24{ }^{80}$ Other researchers have quantified that effort at $\$ 43.80$

\footnotetext{
77 Eric J. Johnson et al., On the Depth and Dynamics of Online Search Behavior, 50 MGMT. SCI. 299 (2004).

${ }^{78}$ Erik Brynjolfsson, Astrid A. Dick \& Michael D. Smith, A Nearly Perfect Market? Differentiation us. Price In Consumer Choice, 8 QUAN. MARKET ECON. 2 (2010).

79 Lynn Silipigni Connaway, Timothy J. Dickey \& Marie L. Radford, “If It Is Too Inconvenient, I'm Not Going After It:" Convenience as a Critical Factor In InformationSeeking Behaviors, 33 LIBR. \& INFO. SCI. RES. 179 (2011).

${ }^{80}$ Anindya Ghose, Panagiotis G. Ipeirotis \& Beibei Li, Search Less, Find More? Examining Limited Consumer Search with Social Media and Product Search Engines, in THIRTY THIRD INTERNATIONAL CONFERENCE ON INFORMATION SYSTEMS (2012).
} 
per page. ${ }^{81}$ Brynjolfsson et al. found that the benefits from searching lower screens equal $\$ 6.55$ for the median consumer. ${ }^{82}$

Not only are search costs high in terms of cognitive cost and effort, but firms may in fact strategically increase them. Glenn Ellison and Sara Fisher Ellison have identified internet firms' strategy of intentionally obfuscating pricing, making consumer search more difficult thereby allowing firms to raise prices. The authors link these strategies to high observed levels of price dispersion, which suggests a less than perfect market. ${ }^{83}$

In short, a considerable body of evidence shows that consumers face high search costs, and these costs affect consumer behavior and pricing. If consumers face significant costs, then a search engine that uses habit and web design to reduce these costs could have significant competitive advantages-perhaps rendering it the "lowest cognitive cost"/minimum spanning tree portal to the web. This vision of consumer behavior and search would suggest a new and different type of essential facility. The empirical evidence demonstrating high search cost suggests that, in fact, Google could operate as an essential facility. Through System 1 habituation and strategic acquisition and provision of key internet resources like YouTube and Gmail, Google provides a unique low cost portal to the web. Switching costs to other firms is too high because competitors face a chicken-and-egg problem in replicating this low cost access: the lowered cost only comes through System 1 habituation, and searching competitors requires consumers to use System 2. More research, of course, would be necessary to establish whether this story is borne out by the facts.

\section{RESPONDING TO OBJECTIONS}

Applying behavioral economics into antitrust and consumer protection regulation are very controversial and very much in the news. The Obama administration has embraced much of behavioral economics-or at least has embraced individuals who have embraced them. For instance, Cass Sunstein, a leading exponent of behavioral

\footnotetext{
${ }^{81}$ Sergei Koulayev \& Ting Wu, Search With Dirichlet Priors: Estimation and Implications for the Price Elasticity of Demand (March 2010), available at http://ssrn.com/abstract $=1305665$.

82 Brynjolfsson et al., supra note 78.

${ }^{8} 3$ Glenn Ellison \& Sara Fisher Ellison, Search, Obfuscation, and Price Elasticities on the Internet, 77 ECONOMETRICA 427 (2009).
} 
economics, recently served as the administrator for Office of Information and Regulatory Affairs. ${ }^{84}$ The recently created Consumer Financial Protection Bureau also boasts noted behavioral advocates in its management ranks, notably Harvard economist. Sendhil Mullainathan.

The ascendency of behavioral economics in policy circles-in addition to important scholars advocating its use in antitrust law ${ }^{85}$-has prompted a vigorous scholarly response. Notably, Joshua Wright, now a commissioner at the FTC, has written several attacks (along with coauthors Judd Stone ${ }^{86}$ and Judge Douglas H. Ginsburg of the U.S. Court of Appeals for the D.C. Circuit ${ }^{87}$ ) on the use of behavioral economics as a basis for regulation and antitrust regulation in particular.

Wright \& Stone identify several cognitive or behavioral biases as central to the claims to behavioral economics and reiect each as forming a sufficient basis to abandon the rational actor model for antitrust regulation. Among these important biases are (i) contextualizing biases, i.e., the endowment effect which makes individuals "reluctant to sell a good endowed to them when offered a sum greater than they are willing to pay to acquire the good" and (ii) self-control problems, such as hyperbolic discounting, discussed above, and optimism bias in which people underestimate the probability of bad results. ${ }^{88}$

In rejecting these biases as relevant to antitrust law, Wright and Stone state:

Behavioralist advocates marshal an impressive collection of laboratory and field evidence illustrating some deviations from expectations arising out of pure

\footnotetext{
84 Mike Dorning, Obama Adopts Behavioral Economics, BLOOMBURG BUSINESSWEEK MAG. (June 24, 2010), http://www.businessweek.com/magazine/content/10_27/b4185019573214.htm.

${ }_{55}$ See Avishalom Tor, The Fable of Entry: Bounded Rationality, Market Discipline, and Legal Policy, 101 MICH. L. REV. 482 (2002); Maurice E. Stucke, New Antitrust Realism, 2 COMPETITION POL'Y INT'L: ANTITRUST CHRON. (Jan. 2009) (for prominent advocates of behavioral antitrust).

86 Joshua D. Wright \& Judd E. Stone, Misbehavioral Economics: The Case Against Behavioral Antitrust, 33 CARDOZO L. REV. 1517 (2012).

87 Joshua D. Wright \& Douglas H. Ginsburg, Behavioral Law and Economics: Its Origins, Fatal Flaws, and Implications for Liberty, 106 NW. U. L. REV.1033, 1036 (2012).
}

${ }^{88}$ Id. 
rational choice. What this evidence fails to provide, however, are either necessary or sufficient conditions for situations in which those biases may affect individual or firm decision-making and those situations in which they do not. 89

They seem to dismiss behavioral economics as merely adding occasional irrationalities to otherwise rational human beings, i.e., sometimes we hoard stuff or succumb to the immediate gratification of drinking to the higher but longer term payoff to studying..$^{\circ}$ Viewed in this way, behavioral economics sometimes says, "We're nuts," but cannot really provide an entire-or even a strong partial-theory as to when we will be nuts.

Wright and Stone seem to adopt, however, a rather crimped definition of "pure rational choice." The gravamen of Kahnemann's, Twersky's, and Simon's work is that, in relying on heuristics or in adopting certain biases, people are behaving rationally. System 1 is rational; it has evolved over time to offer individuals a low-cost way of dealing with cognitive burden, and it generally works well enough. While it may come to different answers than the more analytic System 2, System 1 effectively optimizes limited cognitive resources and, in this sense, is perfectly rational. In other words, as Herbert Simon argued decades ago, it is not perfectly rational to calculate out to the sixth significant digit the expected utility of all our decisions. The effort of calculation is too great. Instead, we must optimize our limited cognitive resources.

The anti-behavioralists forward at least four other main objections. Wright and others argue that (i) the behavioralists fail to provide a convincing account of individual biases aggregating up to

89 Wright \& Stone, supra note 86 , at 1522.

90 See also Gregory Mitchell, Why Law and Economics' Perfect Rationality Should Not Be Traded For Behavioral Law and Economics' Equal Incompetence, 91 GEO. L. J. 67, 73-74 (2002) ("To be clear, the problem identified here goes beyond the trivial claim that behavioral law and economics employs an abstract model of behavior. Rather, the problem is that behavioral law and economics 'proceeds on the basis of inaccurate understandings of judgment and choice.' Whereas law and economics assumes too much rationality on the part of legal actors as an empirical matter, behavioral law and economics errs by assuming too much irrationality."); see also Gregory Mitchell, Taking Behavioralism Too Seriously? The Unwarranted Pessimism of the New Behavioral Analysis of Law, 43 WM. \& MARY L. REV. 1907, 1945 (2002) ("In fact, when one examines the actual data gathered by decision researchers rather than just summary presentations of the data, one finds that at least a significant minority and often a significant majority of the subjects provided the 'right,' or rational, answer to the judgment or decision problem under consideration."). 
firms in a meaningful and predictable way;91 (ii) regulators may fall victim to the same behavioral biases as those whom they regulate, rendering any regulation imperfect or utterly ineffective;92 (iii) the failure to identify the "necessary or sufficient conditions for situations in which those biases may affect individual or firm decision-making and those situations in which they do not"; 93 and (iv) libertarian concerns that behavioral economics prevents individuals from making mistakes and learning from them. ${ }^{94}$ None applies to the argument urged in this Article.

First, it does not seem as if the first objection, aggregating individual biases to firms, is applicable. The Article does not suggest Google is behaving according to System 1. Rather, it is cleverly taking advantage of System 1 behavior of consumers who face high search costs. Similarly, the second objection-that regulators share the same biases-does not have much application. Again, this Article does not suggest that people are irrational; rather, that internet design and habit create different search costs for consumers using different search engines. Regulators' work simply does not involve the type of trade-offs that internet search does.

The third objection, relying on the work of Gregory Mitchell, has perhaps greater application in this instance. As Mitchell points out, many of the behavioral economic biases have been identified by psychologists in the laboratory setting under limited conditions. Because one cannot easily generalize these conditions, one cannot identify on a global basis appropriate for regulation the "necessary or sufficient conditions for situations in which those biases may affect individual or firm decision-making."95

91 Wright \& Stone, supra note 86 , at 1523-24.

92 Id., at 1522, 1530-34; see also Jonathan Klick \& Gregory Mitchell, Government Regulation of Irrationality: Moral and Cognitive Hazards, 90 MINN. L. REV. 1620, 1628 n.20 (2006).

93 Wright \& Stone, supra note 86, at 1522; see also Gregory Mitchell, Libertarian Paternalism Is an Oxymoron, 99 NW. U. L. REV. 1245 (2005).

94 Joshua D. Wright \& Douglas H. Ginsburg, Behavioral Law and Economics: Its Origins, Fatal Flaws, and Implications for Liberty, 106 NW. U. L. REV.1033, 1036 (2012) ("We argue that so long as libertarian paternalism ignores the economic welfare and liberty value of allowing individuals the freedom to err, it will fail to achieve its goal of increasing welfare without reducing liberty and will pose a significant risk of reducing both.").

95 Wright \& Stone, supra note 86, at 1522 (citing Gregory Mitchell, Libertarian Paternalism Is an Oxymoron, 99 Nw. U. L. Rev. 1245 (2005)). 
However, that objection has teeth only if you view behavioral economics as simply identifying weird human tendencies that for some reason make humans deviate from the pure rationality of homo economicus. The idea sketched in this Article makes no such claim. Rather, building off Simon's notion of bounded rationality and Kahnman's psychological account of System 1's economization of limited cognitive results, this Article shows how perfectly rational tendencies to reduce cognitive cost can lead to one dominant web search portal. These claims are, in theory, perfectly generalizable. One could in theory specify the necessary and sufficient conditions for these claims' applicability. 96

Fourth, this Article's contribution is only to suggest a different way for thinking about firm dominance on the Internet. Remedies or regulatory interventions were not yet discussed so it is not clear whether these issues would involve any state intervention that would impinge upon personal liberty in ways Wright and Ginsburg might object to. Further, any remedy that reduces search costs globally is unlikely to raise liberty concerns as such a remedy would make information more easily accessible. The ideas here do not involve what Wright and Ginsburg fear: a regulatory regime that labels certain preferences as behavioral and "irrational" and then "identif[ies] which of the multiple selves' decisions expresses the individual's "true" preferences for the purposes of welfare analysis." 97 Rather, seeing how human beings experience the cost of search simply builds upon accepted economic notions of choice and preference.

\section{CONCLUSION}

The FTC's decision was one of the first efforts in the development of new regulatory paradigms for the regulation of on-line activity. The FTC, however, simply applied one conventional model for understanding economic behavior. This article suggests a different understanding of how online activity changes economic behavior and argues for its plausibility. We stress that this article explores only the plausibility of this alternative approach. The extent to which System 1guided decision making leads us not to make perfectly rational decisions that we might otherwise make-and thereby hurt competition in search-is an empirical question. We have too little data at this point about how consumers function online to resolve that

96 Wright \& Ginsburg, supra note 87, at 1053.

97 Id. at 1060 . 
question. To collect such data would require a new way of thinking about antitrust and the inclusion of behavioral and experimental data. 